\title{
Non-Delimitation of Incompetency Denotations in Jurisprudence and Law and the Contradiction of some of its Titles to the Law on Non-Litigious Matters
}

\author{
Professor Dr. Sorush Niknamian \\ Board Member of Weston A Price Foundation, Washington DC, USA \\ E-mail: so.niknamian@gmail.com
}

\begin{abstract}
:
"Incompetency" literally means prohibition and it is commonly used to point to an individual being deprived of his rights to take possession of his properties and his financial rights by the law. And, in other words, the incompetents are the individuals that do not possess "the legal capacity to enjoy a certain right" and are deprived from taking possession of their properties and if such a taking possession of the properties by an incompetent occurs, it is invalid and cannot take effect.In the legal system of Islam, the individual with a sort of a disease that features certain types of conditions leading to the weakness of the mind or insanity is called an incompetent. But the example cases of the incompetent and incompetency have not been delimited in the jurisprudence and law. Thus, the investigation of the instruments of incompetency from the perspective of the jurisprudential texts and the statutory provisions via offering an assumption indicating the non-delimitation of the incompetency instruments scope has resulted in conflicts in the non-litigious affairs law with the civil procedure, the necessity to rethink the causes of insanity as one instrument of incompetency in the civil law, the centrality of the incompetency for its setting the ground for the exertion of the law and the non-litigious affairs regulations as well as the incompetency of some patients with nervous diseases like hysterical conversion and dissociative hysteria and so forth.

Therefore, conceptualizing the incompetency, the present study aims at assessing, then criticizing and investigating, the proofs offered by the proponents and the opponents of the incompetency of the patients with hysteria so as to consequently conclude an assumption regarding the hysteric patients' incompetency and the relevant contradictions, if any, with the non-litigious matters law and civil procedure.
\end{abstract}

Keywords: incompetency, incompetent, non-litigious matters, psychopathic patients, hysteria

\section{Introduction:}

The non-litigious matters, as defined by the legislator, encompass the affairs for which the courts are obliged to take measures and adopt decisions without their trial being pending on the emergence of discrepancies and disputes between parties and the filing of lawsuits by them (Hasani Nik, 2010, 459). One important jurisprudential and legal discussion has been put forth under the title of "incompetency" and it considers the individual featuring 
"incompetency" as being legally incapacitated for performing legal measures due to some defection or absence of legal capacity for one or another reason.

One issue that is frequently applied in jurisprudence and law is the same topic of "incompetency" and "special diseases" that are proposed in discussions on the "enjoyment of rights legal capacity" and it is found completely related reasonably to the legal nature casted in the Article (1) of the non-litigious matters. But, the law seems to have not delimited its examples and boundaries for which case it has taken a still position and it apparently has numerous outcomes and effects in the area of private law and civil procedure. So, in order to avoid any mistake therein, there is a need for some researches to bridge the gaps in the investigation of jurisprudential and legal dimensions of the issue.

Now, the current research paper intends to, meanwhile investigating the newly-introduced concept of "special hysteria disease" under the title of "incompetency" and expressing the discrepancies in the definitions by the jurisprudents and the jurists, and notably the law has taken a silent stance in this regard or otherwise has taken the issue into consideration under other concepts, conclude a procedural unity in the trial cases of the issue in the civil procedure.

Thus, the present study has been carried out based on a descriptive-analytical method and the data are gathered based on library research and running an analysis over the extant resources as well as via inquiring ideas and notions from the expert jurisprudents and jurists. The data collection tool has been note-taking, information banks, computer networks and the use of specialized software.

\section{Statement of the Problem:}

The incompetency of a patient is inter alia the topics that has long been posited in the Islamic jurisprudence and it has been an area for the exchange of thoughts and notions by the prominent scientists expert in this field like Sheikh Tusi (Al-Mabsout, 4: 44), Allameh Helli (Qava'ed Al-Ahkam, 2: 531), Shahid Sani (Masalek Al-Afham, 6: 310), Fakhr AlMohaqqeqin (Izah Al-Fawa'ed fi Sharh Eshkalat Al-Qava'ed, 2: 593), Mohaqqeq Korki (Jame'e Al-Maqased fi Sharh Al-Qava'ed, 11: 94), Sheikh Mofid (Al-Moqna'eh, 671), Sayyed Morteza (Al-Intisar, 224), Ibn Edris (As-Sara'er, 3: 200) and Ibn Borraj (AlMuhzab (1: 420).

In between, the ideas by some Sunni jurisprudents (Zahili, Al-Fiqh Al-Eslamy Wa Adellataho, 5: 451) are also noticeable. The important point here is that although the civil law of our country has been derived of the Islamic jurisprudence and influenced by the most popular ideas of the most famous jurisprudents, they all seem not to have enumerated diseases as the instruments of incompetency and they all have adopted a silent position in regard of the extensive verdicts related to the patients' taking possession of their properties, especially concerning the patients with special diseases like hysteria and so forth. 
The disagreement between the jurisprudents, on the one hand, and the lack of legislator's attention to such an important issue, on the other hand, raises this question that why a certain patient has not been considered incompetent in the Islamic jurisprudence? In other words, it can be claimed that being inflicted with a disease acts as an independent cause to influence the legal capacity of the patient meeting the conditions of growth and maturity so as to render an individual incompetent; or, it has to be admitted that the mere adherence to the surface of some news and narratives as well as considerate feelings regarding the patient's heir(ess) and prevention of any harm from being imposed on them are the reasons why an exceptional verdict has not been decreed regarding the incompetency and incompetent.

The present study deals with the exploration of the proofs offered by the proponents of incompetency and it seems that it is via scientific criticism and investigation of these proofs that an assumption can be constructed in regard of the idea that some patients should be declared incompetent and that there is no need to try their cases in the courts in discussions on the rules of procedure.

\section{Who is a Patient?}

In Islamic jurisprudence, "patient" designates a special expression and concept one sort of which can be included by the abovementioned jurisprudential decree and that is a patient who is on the verge of death. There are numerous definitions offered for such an expression in the jurisprudential texts. Some of these titles have been said to correspond to diseases that are diagnosed as lethal and dangerous by the specialized physicians (Sheikh Tusi, AlMabsut, 4: 44 and Ibn Qodameh, Al-Moghni, 6: 505) and some others have prescribed the common law rulings as the substitute for the physicians' diagnosis and believe that if a disease is pointed out as deadly by the common law it will suffice in favor of authentication of an individual being a "patient" and no other condition is necessary in proving it being of a lethal nature (Najafi, Javaher Al-Kalam, 9: 283). In the meanwhile, some jurisprudents have stepped beyond this boundary and consider any patient who dies as a result of any disease as being on the verge of the death; although there is reached a consensus regarding the disease not being dangerous or even if the patient basically dies of a cause other than disease (Allameh Helli, Qava'ed Al-Ahkam, 2: 592). On the contrary, some others have made efforts to adjust this latter definition via adding the causal condition of disease in the occurrence of some one's death. Based thereupon, only those of the patients can be considered on the verge of death if $\mathrm{s} / \mathrm{he}$ dies in the course of a lethal disease (Mohaqqeq Helli, Shara'ee Al-Eslam, 4: 173).

Considering all the aforementioned definitions, it has to be stated that the patient on the verge of death is the one whose lethality of the disease has been diagnosed and affirmed by the physicians and that has to be not in a typical and general type, but in a specific manner and via examining the patient. Besides, the patient should become all of a sudden incapable of performing daily and routine life activities and finally dies as a result of the 
same disease. Therefore, the patients whom are not medically expected to recover but they are still not demonstrating any sign of death and they also do not feel the risk of death and exacerbation of their status should not be considered as patients on the verge of death hence are excluded from the inclusion circle of the foresaid jurisprudential verdict. Thus, the patients with hysteria, cancer or MS or other diseases of the like who wearily spend a lot of time coping with their disease are not examples of the definition and they are to be considered on the verge of death only when they exhibit symptoms of death.

As it was noted, the tried cases and the decisions made in the courts without the occurrence of any discrepancy and without the proposition of dispute between the parties are called non-litigious matters and seminally seem to be completely in disagreement with the Article (2) of the civil procedure that states "no court can try a lawsuit without it being demanded by an individual or several interested individuals or the lawyer or the deputy or the legal representative of them" because the aforementioned article knows the submission of a lawsuit to the courts by a claimant as more superior but in the non-litigious matters in which no law case has been proposed by a plaintiff or a claimant, the court on its own initiative takes into consideration the competency of an incompetent person and takes measures in line with trying the case. In other words, the civil procedure asserts that "the court is prohibited from trying a case unless a lawsuit is filed and submitted to the court, so not only the road to a substantive trial has been blocked but also even trying the existence or the absence of the lawsuit conditions are made forbidden leave alone the issuance of writs indicating the rejection of a claim or the termination of a lawsuit (Shams, 2001, 316).

According to the fact that the term "incompetency" is usually used as an antonym to the "legal capacity for an enjoyment of certain rights" and the "incompetent" is a person who cannot perform legal actions due to some defection or for an absence of legal capacity, therefore, in order to recognize the proposed issue, it is necessary to provide the reader with the definitions on the key terms and important expressions used herein like incompetency, legal capacity, legal capacity for an enjoyment of a right, legal capacity for use of certain rights, types and descriptions of incompetency so as to make it readily discernible to the readers.

Legal capacity generally means the individual's qualification for taking possession of certain rights and fulfillment of obligations. In this meaning, the perfect legal capacity is intended but it happens occasionally that the phrase only refers to the ability for taking possession of certain rights and actualization of them and this is the specific aspect of legal capacity (Safa'ee and Ghasemzadeh, 2013, 200).

Articles (210), (190-212) can convey the idea that legal capacity means the qualification for the actualization of one's own rights for the most part. The legal capacity for taking the possession of certain rights in Persian means "the legal capacity for the enjoyment of certain rights" (Emami, 1977, 204: 1) and in another denotation it means "the individuals" 
legal capacity" (Ja'afary Langarudi, no date) and the Arab jurists realize it as "the legal capacity for the fulfillment of obligations" (Al-Sahury, 1952: 601).

"The legal capacity" for taking possession of one's own rights does not necessarily mean the "legal capacity" for the actualization of them because it is quite possible for an individual to have a right but be unable to fulfill it. The individual who has a right or has to fulfill a certain obligation can take possession of his right or fulfill his duty when s/he possesses the ability and the qualification for doing so. In Iran's law, such a legal capacity is called the legal capacity for the use of one's own rights or jus habendi (Safa'ee and Ghasemzadeh, 2013, 201).

The legal premise for the legal capacity for the right to enjoy: is being a human being. As soon as the existence and the personality of a human being are formed and s/he stepped into life, s/he can take possession of certain rights. The human beings even have the legal capacity to enjoy certain rights even before being born that is called imperfect legal capacity. And, such a legal capacity lasts till death. But the underlying premise of the legal capacity for use is laid on the ability to make distinction and comprehend because the natural volition that is necessary for carrying out the legal deeds does only reside in the individuals having the distinction faculty (Al-Hakim, 2004, 107: 1).

Since the regulations pertaining to the legal capacity are connected to the expediencies of the society and are especially important, these regulations are enumerated among the imperative law pertaining to the public order (Abu Al-Sa'oud, 1990: 109).

Generally, the regulations enacted for the support of the personality, the freedom and the healthiness of an individual's volition are connected to the public order and the individuals cannot reach to agreements against them and such agreements are invalid and devoid of any effect based on the conventional issues related to the legal capacity deprivation, including the legal capacity for the enjoyment and owning certain rights (Safa'ee and Ghasemzadeh, 2013: 204).

The question raised here pertains to a survey of the standpoints of the statutory provisions, Imamiyyeh Jurisprudence and General jurisprudence in confrontation with the raid of the outcomes resulting from the decisions made by the courts without any submission of claim or lawsuit regarding the incompetent individuals.

It seems that the instruments of incompetency differ in the Islamic jurisprudence from the statutory provisions and there are also very important cases that can typically render an individual incompetent but have not been taken into account by the jurisprudents and the law.

Incompetency can be manifested in two forms. The first is general incompetency in which the individual is generally prohibited from fulfilling rights and performing legal actions. For instance an insane person has to be considered generally incompetent because it 
encompasses all his legal actions and the insane person, due to the absence of will, cannot perform any legal action, whether be it a contract or be it a unilateral act of a legally valid consequence. A minor person is also considered generally incompetent because the minor, except in exceptional cases, cannot fulfill his or her rights in person (Safa'ee and Ghasemzadeh, p.2013, 211).

The special incompetency encompasses the deprivation of certain occupancy rights not all of them. As a specimen, the incompetency of a mentally retarded individual or a not fully grown individual is to be considered as a special incompetency because it only incorporates the financial affairs. The insolvency of a merchant is a type of special incompetency because it is restricted to the domain of financial occupancy as termed by the creditors (Safa'ee and Ghasemzadeh, 2013: 211).

In supportive incompetency, the legislator intends to protect the incompetent individuals but in suspicious incompetency the intention resides in protecting the others' interests. As an example, the incompetency of an insane, a minor or a mentally retarded individual is of the supportive type because these individuals cannot administrate their affairs the way they have to for such reasons as mental disorders or deficiencies but the insolvency of a bankrupt merchant is a suspicious incompetency because the preservation of the creditors' rights and prevention of disadvantageous financial occupancy in regard of the creditors come first (Ibid).

The classification of incompetency to "suspicious incompetency" and "supportive incompetency" (Al-Najafi, no date, 4: 26), as well, has been carried out by some Imamiyyeh jurisprudents (incompetency can be directly ruled by the law or by the ordinance of a court that are termed legal incompetency and judicial incompetency, respectively). As a specimen, a minor's incompetency has been ordered by the law but the incompetency of an insane person, suffering insanity after maturity, as well as the incompetency of a bankrupt merchant that requires the court's verdict is a judicial one (Safa'ee and Ghasemzadeh, 2013: 212).

In some of the cases, incompetency is ruled based on the absence of understanding, reason and will and in others the incompetency is laid on the foundation of defection or inadequacy of the volition in such a manner that an insane's incompetency is of the first type and an discerning minor or a mentally retarded person's incompetency is of the second type (Ibid).

In the Holy Quran, there are AYAT on which the jurisprudents and the jurists have documented their rulings (Shahabi, 147: 2, 9: 13 to 150). The majority of these AYAT pertain to the minors or the mentally retarded individuals including the followings: "test the ones whose father has died till they reach puberty then when you figured out growth in them return their properties to them" (SURAH: NISA'A: 5) or "do not assign the mentally retarded individuals [natural fools] to the authority of your personal possessions" (BAQARAH: 282) or "whenever the debtor is a fool or a weak (minor) individual and 
could not dictate [the item of debt], but s/he has to write it down in regard of justice" (AN'AM: 52) or "do not get close to the properties of orphans unless it is to their advantage the best way possible till they reach sexual maturity and mental growth" (ESRA'A: 34).

There is a disagreement between the holy Quran interpreters in defining the maximum growth. Some have realized it as autoeroticism, some others know it as perfection of wisdom and some others consider it reaching to an age of thirty and others condition it to thirty three years of age (Safa'ee and Ghasemzadeh, 2013, p.215). The late Allameh Tabataba'ee has described the maximum growth as mentioned in the AYA as meaning "the maximum extent of the physical vigor and the termination of childhood period" (Mehrizi, 1993, 375, 376).

Besides the proofs from the Holy Quran, there are numerous AHADITH and Narratives regarding the different kinds of incompetents. The issue has been well investigated in the authentic books of narratives and the jurisprudential books, including in "Raf'a Al-Qalam An Salaseh: An Al-Ssabi Hatta Yahtalem wa An Al-Majnoon Hatta Yafiq wa An Al-Na'em Hatta Yantabeh" in which the obligations are lifted from three groups of incompetent persons, i.e. from a child till reaches to an age of nocturnal emission, from a fool till s/he recovers and an slept person till s/he wakes up (Wasa'el Al-Shi'ah, Hadith).

According to jurists, the legislator seeks the accomplishment of certain goals in the creation of restrictions on incompetents and also in the establishment of a legal provision called "incompetency". These goals and motives are altogether called the wisdom behind the justification of incompetency. The intentions therein are twofold: supporting the interests of the incompetent and protecting the others. Prohibiting the incompetent from performing legal actions and assigning the custodianship to a guardian or the parents, the legislator tries to preserve the legal rights and financial properties of the incompetent persons and defend them against any sort of harm hence prevents the incompetent from becoming a burden on the shoulder of the society and wasting the nation's properties. Moreover, this way the expediency of the creditors is also observed and they will be protected from suffering a loss (Safa'ee and Ghasemzadeh, 2013: 216).

Inter alia the different types of incompetency, the topic that obeys a special legal regime and deserves investigation in the civil law and, in other words, the thing about which there is a general theory is the supportive incompetency that has been specified to preserve the rights and the interests of the minors, the fools and the maniacs. The legal premise of the supportive incompetency is the absence or the weakness of wisdom or volition (Al-Kashef Al-Aza'a, 1982, 170: 30).

There is a need for the existence of a natural or a legal volition for the fulfillment of legal actions and such a will entails the presence of concentration and perception and because the incompetent persons lack such a concentration and volition and the mentally retarded individual (discerning minor and fool) have defective faculty of concentration and volition, 
thus they cannot directly take effective measures in performing their legal actions so they are prohibited from their occupancy rights by law (Safa'ee and Ghasemzadeh, 2013: 217).

But, as for the suspicious incompetency, the legal premise of the incompetency is not the lack or the defectiveness of the will rather it is protecting the other individuals and the creditors. For instance, a bankrupt individual, as it was mentioned without being inflicted by a mental disorder or deficiency, is restrained from certain financial occupancy rights so as to not be able to carry out actions that damage the creditors' rights (Ibid).

It has to be emphasized again that because based on the article on the non-litigious matters, "the courts do not need two conflicting parties in trying the non-litigious matters or, more precisely, the individual who provides the information does not necessarily need to be an interested party, or there is no need for the presence of two parties having disagreement over a topic meaning that the mere knowledge of the court of the issue and the claim by one of the two parties, interested or not, suffice the trial of non-litigious matters for which appropriate decisions have to be made. For example, whenever the hereditament of a minor is being wasted by the custodian or the other heirs or heiresses, each of the minor's relatives or other ordinary persons can inform the court of the issue and the court has to make a proper decision regarding it; or, the fact that there is no need for the confirmation of the members and the heirs and heiresses' disagreement in partitioning of the succession. The court can by the sole claim of one of the parties take appropriate measures and make proper decisions (Abazary Foumashi, 2013: 11). And, additionally, according to the fact that the non-litigious matters' law is generally a rule supporting the incompetent individuals and that it has been codified and enacted to bring about the grounding for non-wastage of the incompetents' rights, thus the current research paper specifically deals with the important topics of the discussion on the incompetency.

The important issue in the present study is the investigation of the instruments of incompetency in Imamiyyeh Jurisprudence, general jurisprudence and the statutory provisions that seem not to have been taken into consideration due to the extensive scope of the incompetency in the jurisprudential texts and statutory provisions and this hopefully paves the way for the enforcement of non-litigious matters rules so the upcoming parts deal with the instruments of incompetency.

There are numerous instruments considered as the underlying causes of incompetency in Imamiyyeh Jurisprudence but the Imamiyyeh jurisprudents usually mention six causes as contributing factors to incompetency in their books thereon. These six causes are: 1) minority; 2) foolishness; 3) insanity; 4) insolvency; 5) disease leading to death; and, 6) slavery (Safa'ee and Ghasemzadeh, 2013: 218).

Besides the abovementioned instruments, some jurisprudents have mentioned other instruments like the incompetency of a mortgager in respect to the exact property mortgaged, the buyer's incompetency in respect to the item of sale before price payment, 
the seller's incompetency in respect to the price before the submission of the item of sale and the incompetency of an infidel that is accepted (Ibid).

Shahid Sani states in "Masalek" that "limiting the instruments of incompetency to six cases is an artificial and deductive classification which is not based on reason and there are other instruments for the incompetency (Ibid).

The question proposed in the present study pertained to the status of a hysteric patient in respect to the instruments of incompetency and the disease is sometimes expressed in a psychotic form that makes the individual suffer absolute collapse of discretion, perception, consciousness and decision-making volition and according to the fact that the obligations are assigned to the human beings based on having free will and a faculty for making distinctions and the individual lacking the sense of right and wrong is not only freed from the religious obligations but his or her legal actions are also invalid, thus these individuals cannot administrate their own affairs, need protection and the society should principally support them.

The distinct sign of hysteria expression is the involuntary loss of functioning and/or reactive disorders in the nervous system, voluntary or conscious reason activities (Alaviyan, 2014: 101). Hysteria is a psychological disease that is manifested somatically. Various pains, anxiety, digestive disorders, disorder in the sexual relations, anger and other symptoms are inter alia the signs of hysteria (Ganji, 2004: 250).

Hysteria is a psychological disorder that is diagnosed with no existence of a specified medical justification by one or several nervous signs like organ paralysis, blindness, lack of sensation and so forth (Nazighi, 2010: 5).

The hysterical conversion is more prevalent in women as compared to the men. The expression of the disease is substantially caused by the mental and social laggardness. The thoughts defensive mechanism is the distinct feature of the hysterical conversion (Shamloo, 2004: 140).

Sensory disorders, muscular paralysis, motor disorders, interior body dysfunctions are amongst the other symptoms of Hysteria (Alaviyan, 2014: 130).

In each of the senses like sight, hearing, tasting, smelling and others, the hysterical disorder occurs in the form of complete senselessness, relative senselessness, extreme sensitivity or abnormal sensations such as tingling or vision problems or in relation to audition, deafness is the distinct characteristic of a hysteric individual. As for the sense of touch, the senseless is usually observed in the areas pertaining to gloves and socks. Senselessness in the other regions of the skin like in the head, neck and body might occur, of course less frequently (Shamloo, 2007: 141). 
The muscular paralysis symptoms in hysteric patients: the individual's ability for performing the voluntary actions is either totally or partly lost. The patient sometimes becomes paralyzed on both feet or in half of the body. The lack of muscular activity might even influence the vocal system of the patient in such a manner that $\mathrm{s} / \mathrm{he}$ might lose the ability to talk or only produce weak sounds (Alaviyan, 2014: 103).

The motor disorders resulting from hysteria are numerous and diverse, but the most wellknown and prevalent of them are: jerking, shaking, pseudo-epilepsy attacks, deafness and stammering. Also, one of the interesting sings of the hysteria is a disorder called astasiaabasia. The individual with such a disease cannot stand on his feet or walk and he can perform complex movements when lying on his back like the moves carried out when cycling (Shamloo, 2007: 142).

Jerking is the major symptom of the disorder that has been categorized under the broad title "hysteria" and it is a type of disorder in the general moves of a part of body that is manifested in the form of jerks. Jerking is defined as a sort of fast and involuntary twitching of a group of muscles around a main part of the skeleton. Regarding the involuntary movement of the muscles governing the production of sounds and words and breathing through the vocal tract, the production of involuntary voices or words is called jerking. Jerking as the major sign of the body's motor disorder should be considered as the other involuntary moves of the body (Alaviyan, 2014: 103).

In hysterical conversion, there is no typical separation between the personality parts, so, because the considerable blurring of the reason and the gradual decline of the consciousness level does not appear in this disorder and the individual is fully aware of his conducts and behaviors, so such an individual is to be held relatively responsible for his actions. That is because he is not like a healthy individual who is perfectly held accountable for what he does (Alaviyan, 1994: 171).

The assigning of the obligations is radically based on having a power to distinguish right from wrong and the volition and the not only the religious obligations are lifted from the individual lacking the faculty of distinction and volition but also his actions cannot legally take any effect. Since such individuals cannot administrate their own affairs and need protection, the society has to support these individuals. The distinct specimen of such individuals with such a disease is a maniac or a foolish person who is supported by a court's sentence based on a pre-diagnosis by a physician. But, there are those who are not to be categorized in the group of foolish persons hence be considered equal to them but they psychologically and physically feature abnormal conditions, to wit even though they are not insane they cannot make proper decisions due to having extreme psychological debilities and disorders and they usually make mistakes and have weaknesses that cannot be neglected. The legislator has not contemplated any strategy in respect to these individuals. It might appear in the first place that this is a correct method and the individuals should not be restricted in their freedoms for various excuses but being realistic and 
offering reasonable and logical supports to the needy individuals does not seem to impose a harm on the individual freedoms rather it acts as a barrier to the misuses of these freedoms and it is to the advantage of the society members one way or another (Safa'ee and Gha'emzadeh, 2013: 278).

In the current statuses of the things, none of the psychologically ill individuals cannot be grouped with perpetual or temporal fools without first it being diagnosed by a specialized physician who can make judgments in this regard, but can't they be considered as not fully grown individuals due to the weakness of volition and the defectiveness of the mental faculty and so forth? (Ibid)

One may say that an immature person is weak in financial affairs but their weakness is not limited to the financial matters. This is true. But, whenever a mature and wise individual loses the power to manage part of his affairs, then his actions are regarded as devoid of any effect by the legislator. Can't the criterion of this latter axiom be used for the psychologically -ill individuals? (Ibid, 279)

It is not far from imagination to consider a unitary criterion or a priority comparison, even though the creation of incompetency without it being explicitly ruled by the law seems objectionable, the legislator is required to devise strategies for such individuals and codify and approve regulations in this regard the way some of the Islamic countries, following the lead of Hanafi Jurisprudence, have accepted relative lapse of reason or psychosis. Egypt, Syria, Iraq and some other countries like France have classifications of the mental faculty disorders (Ibid).

The issue is also posited about the individuals who are in a state of (constant or temporary) unconsciousness or coma. In this case, as well, they can be considered as mentally defective and therefore be supported by some sort of a protective regime, although confirming this issue without it being explicitly opined by the legislator is not devoid of fault (Ibid).

If this class of the people performs legal actions in a state of lapse of reason and volition, their actions will be invalid and as if not carried out in case that their lapse of reason is proved. Of course, justification of incompetency is not needed for invalidating these actions and the mere theory of volition (intention) is envisaged sufficient but the establishment of a protective regime for the administration of their affairs, such as guardianship, necessitates incompetency proofs and this is of course a difficult issue to be decreed without it being affirmed by the legislator (Ibid).

In the author's opinion, according to the fact that in hysterical conversion following such factors as sensory disorders, muscular paralysis, motor defectiveness, interior body problems the consciousness level is decreased and the reason suffers a sort of blurriness, the individual with the hysterical conversion should be considered an incompetent person and in dissociative or abstract hysteria, as caused by the pressure of suppressed motives, a sort of separation between the parts of the personality comes about in such a manner that 
the affections and the religious thoughts depart from one another as a result of which the individual apparently forgets a painful incident and takes part of his life to beyond the identification scope of his conscience and reason (Alaviyan, 2014: 104).

Usually, reactions exhibited in the form of forgetting and escape and the multiplicity of personality and sleepwalking form the set of abstract hysteria the common reason behind which is the same factors giving rise to general hysteria with the difference being that in each of the foresaid reactions or in the specific cause thereof there is a predominantly effective cause that brings distinction in them (Kayniya, 2009, 480, 1).

Forgetfulness is a disease that is termed amnesia in medicine and it is expressed abruptly and lasts for an uncertain period of time (Ibid, 145).

Fugue reaction is a combination of amnesia and escaping from one place to another. In a great many of the individuals, the fear of shouldering responsibility is the major cause of Fugue reaction. Some psychologists have stated that there have been patients who have committed crime when in a state of fugue reaction but such cases have been very rare (Shamloo, 2007: 104).

Cometabolism includes performing certain actions like walking, speaking, eating and things of the like at sleep (Ibid). Inter alia the sleepwalking criteria is the fact that a few minutes after waking up the sleepwalker does not exhibit any psychological and behavioral disorder, though s/he may feel dizzy and lack the sense of direction for a short period. In the meanwhile, the symptoms of infectious problems such as the ones seen in diseases like epilepsy should be discarded in the onset and persistence of sleepwalking disorders (Najafi, 2000, 81).

The individual with the multiple personality disorder exhibits completely different intellectual and affective patterns in various times. The multiple personality disorder is amongst the rarest neurotic types of diseases and it should not be mistaken with the dissociative personality disorder that is seen in patients with schizophrenia (Alaviyan, Sough, 105, 139). Personality includes the individuals' external and observable characteristics. It encompasses the aspects seeable by the others (Betholens et al, 1998, 12).

The scales proposed by DSM-IV regarding dissociative personality are:

1) The existence of at least two independent identities or personalities, each with a fixed and separate pattern in perceiving the affections, thoughts about one's own self and the society and the method of communicating with the others.

2) In every cross-section of time, the personalities influence the individual's behavioral styles in a repetitive manner.

3) Inability in remembering the past events in a more intensified manner in respect to the common forgetfulness. 
4) The emergence of such a disorder is not due to the direct physiological factors, especially the toxicity resulting from the use of stimulants or narcotics and/or not for the general status of the patient's physique (like what happens in some secondary attacks). In children, the multiple personality disorder should be distinguished from their imaginations and thoughts regarding their mental playmates that are visible in their playing of the games (Alaviyan, 2014: 106).

In general jurisprudence, as well, like in Imamiyyeh Jurisprudence, there is an array of incompetency instruments but the general jurisprudents exercise a little different method in delimiting and counting the incompetency instruments. They usually speak of such instruments of incompetency as minority, foolishness and insanity and, in the meantime, they point out that there are other major causes like slavery, being on the verge of death and indebtedness. Al-Majalleh (Majallat Al-Ahkam Al-Adliyyeh), as the civil law of the former Ottoman country and an authentic source of Hanafi jurisprudence, introduces the types of incompetent individuals in Article (957) on. Some of the commentators of this same law name seven causes as the underlying factors leading to incompetency in explicating and interpreting the aforementioned articles (Safa'ee and Ghasemzadeh, 2013: 218).

Ali Haydar, the first head of the Supreme Court and the then minister of the Ottoman government and the teacher of Majallat Al-Ahkam Al-Adliyyeh in Astana law school and also a famous interpreter of the Al-Majallat, states: "slavery, minority, insanity and public harm are the instruments on which the jurisprudents have come to a consensus but the exact mentioning of slavery is missing from Al-Majallah. Whether indebtedness, insanity, ignorance (illiteracy) can be enumerated as incompetency instruments or not is a controversial issue. The author points to the cases that in his mind are not common instruments of incompetency and it is explained in the context of the articles (964) on, these cases are: a mischievous expounder (the one whose harmful deceits are clear to the people and he ignorantly makes decrees and he does not care if he lifts the ban of forbidden things or otherwise ban the permissible things) and the unknowledgeable and dishonest physician and also a deceitful poor who lends animals (Ibid: 219).

In another chapter of Al-Majallat, within the context of articles 877 to 880, the patient whose disease leads to death has been somewhat considered as incompetent. Some of the general jurisprudents have used incompetency in its extensive denotation and have mentioned a great many of the cases for incompetency the majority of which pertain to the incompetency the underlying cause of which is a breach of ownership right, such as a customer's incompetency in respect to the item of sale before paying the price and the incompetency of the seller in respect to the price before submitting the item of sale and the incompetency of a person who lends land for burial of the dead and cannot sell it before covering the dead person's corpse and the incompetency of a usurper in his own property being mixed with the usurped property in such a way that they cannot be segregated before compensating for the price of the property taken by force (Ibid). 
In general jurisprudence, the common incompetency instruments are: minority, insanity (sexual foolishness) and lunacy (Al-Jaziry, 1984, 349).

In the Article (1207) of the civil law, the mentioned incompetency instruments are limited to minority, insanity and lunacy. The incompetency caused by these three reasons is the basis of a special statutory provision and obeys a unitary regime because in all of them, the extant incompetency has come about due to the deficiency in the mental power or, in other words, due to the lack of volitional defection or inadequacy and the incompetent individual deserves protection. In such a type of incompetency, the defection resides in the incompetent, and in the today's law, the expression incompetency has not been used for cases that cause prohibition or defection in ownership like the mortgager's incompetency, or the prohibition of occupancy due to it being ruled in the civil law. However, the type of incompetency intended by the civil law is the very protective incompetency.

Therefore, according to what was mentioned up to the this point, since the incompetency covers a vast area and encompasses a lot of meanings in the today's law and it cannot be considered as limited to the financial affairs only, even though the incompetency in the financial matters has been more attentively taken into account by the jurisprudents, jurists and the legislators, it has to be recounted as featuring special issues and verdicts in the nonfinancial matters like in divorcement which is a nonfinancial matter or the confessions made by a minor or a fool regarding the nonfinancial matters all of which can be the subjects of lengthy debates; so, incompetency is not specific to the financial matters in the law of Iran and the legal nonfinancial actions have also been put forth in discussions on incompetency and legal capacity. In confirming the idea it can be stated as a specimen that an insane person, for his perfect incompetency, is prohibited from performing any legal action, including the financial and the nonfinancial ones. Thus, the hysterical person should be considered as an incompetent individual because in abstract hysteria or dissociative hysteria the individual suffers a complete collapse of discretion, perception, consciousness and decision-making volition.

A distinct example of the non-litigious matters is the legal actions on behalf of no party and leaving them unattended untried is undoubtedly unacceptable from the Islam's viewpoint such as taking the responsibility of the endowments that do not have a clear proctor or the guardianship of the children who do not have a certain parent or the will by a dead person in which no specific person has been determined to take the responsibility of the properties and other cases of the like that leaving them undone brings about more intensive problems and it is, of course, far from the taste of the canonical rules and the religious procedures that signify the observation of expediencies in such cases (Amid Zanjani, 2005: 377, 70).

The inclusion of non-litigious matters with such cases is not accompanied by any disagreement and dispute and even there is no necessity for taking the direct tenure of these 
matters by a completely-qualified jurisprudent; rather, he can assign trusted and truthful individuals to the tenure and supervision of these affairs (Ibid).

However, some of the jurisprudents have used the term "guardianship" for the jurisprudent in all of these cases based on the proofs of jurisprudential guardianship and believe that out of his guardianship authority, the jurisprudent can appoint individuals as proctors, custodians, executors and overseers and some others have considered such authorities as being the subjects being in close tie to the topic of Immaculate Imams (peace be upon them)'s agency and deputyship and believe that with the death of the jurisprudent, the entire installations made are revoked and need to be re-determined by a live completely-qualified jurisprudent (ibid).

\section{Conclusion:}

The preset study that was carried out on the incompetency instruments and it has provided the following results due to its being of a great use for the legal actions taken in respect to the non-litigious matters:

1) The contradiction between the Article (1) of the non-litigious matters law with the Article (2) of the civil procedure;

2) The uncertainty regarding the causes of insanity as one if the incompetency instruments in the general jurisprudence, Imamiyyeh jurisprudence and the statutory provisions;

3) The centrality of incompetency issue for the exertion of non-litigious matters law; and,

4) The incompetency of the hysterical patient and the other neurotic and psychopathic patients that has not been considered in the law as well as in the jurisprudential texts.

\section{References:}

- Holy Quran

- Esfahani, Sayyed Abulhassan, (2000), "Wasilat Al-Nijah", $1^{\text {st }}$ ed., the institution for the compilation of Imam Khomeini (may Allah sanctify the sacred soil of his tomb)'s works

- Ardabili, Ahmad Ben Muhammad, (no date), “Zidat Al-Bayan”, $1^{\text {st }}$ ed., Maktabat Al-Ja'afariyyah

- Borujerdy, Tabataba'ee, “Jame’e Al-Ahadith Al-Shi’ah”, v.23, Qom, Iran, Farhange-Sabz

- Helli, Allameh, Hassan Ben Yusuf Ben Motahhar, (1998), "Tahrir Al-Ahkam AlSahri'ah Ala Mazhab Al-Emamiyyeh", $1^{\text {st }}$ ed., v.2, Qom, Iran, Imam Sadeq (peace be upon him) Institute

- Helli, Sayvari, Meqdad Ben Abdullah, (2003), "Kanz Al-Erfan", 1 ${ }^{\text {st }}$ ed., v.2, Mortazavi 
- Hakim, Tabataba'ee, Sayyed Muhsen, (1994), "Mostamsek Al-Urvat Al-Vusqa”, $1^{\text {st }}$ ed., v.12, Dar Al-Tafsir

- Kazemi, Fazel, Horr Ben Sa'ad, (no date), "Masalek Al-Afham Ela AYAT AlAhkam", v.3, no place

- Khomeini, Sayyed Ruhollah, (no date), Tahrir Al-Wasilah", ${ }^{\text {st }}$ ed., v.2, Matbu'at Al-Bohus Al-Eslamiyyeh

- Ameli, Horr, Muhammad Hassan, (1990), "Hedayat Al-Umma Ela Al-Ahkam AlA'emmah", $1^{\text {st }}$ ed., v.6, Majma'a Al-Bohus Al-Eslamiyyeh

- Sayyed Masoud Mousavi Nasab, "forensic psychology", v.1, p.52, Ali Asghar Panahi Matin, Shiraz Medical Sciences University

- Harold, J. Kaplan and Benjamin Saduk, "a summary of behavioral psychiatry", v.1, p.505, tr. Pourafkary, Shahr Ashoub

- Sa'eed Shamloo, (1996), "psychological pathology", v.1, p.303, Tehran

- Ahmad Naraghi, “Awa'ed Al-Ayyam”, v.1, p.513, Qom, Islamic Promotion Office

- Sheikh Ja'afar Kashef Al-Qita'a, "Kashf Al-Qita'a”, v.1, p. 253

- Sayyed Ahmad Khansary, Jame'e Al-Madarek, v.2, p.918

- Golpayegani, “Al-Mo'jam Al-Fiqhiyyeh", v.9, p.90

- Mohaqqeq Helli, Shara'e'e Al-Islam”, v.2, p. 353

- Emami, Hassan, "civil law: individuals and incompetents", v.1, p. 206

- Sheikh Yusuf Bahrani, "Hada'eq Al-Nazerah", v.20, p.378, Islamic Publication center associated with the society of teachers

- Sayyed Muhsen, Hakim, "Mustamsek Al-Urvat Al-Vusqa”, v. 9, p.12, Dar Ehya'a Al-Torath Al-Araby, Beirut 